\title{
Using Environmentally-Themed Videos to Help Extension Promote Good Landscape Management Behaviors'
}

\author{
Laura A. Sanagorski Warner, Alexa J. Lamm, and Joy N. Rumble²
}

\section{Introduction}

Water quality and quantity are major issues in the state of Florida, and water resources can be positively or negatively affected by the way residents choose to fertilize and irrigate their lawns and landscapes. Thus, there is an opportunity for households to use good landscape management practices to protect water resources (Hurd, 2006). UF/IFAS Extension professionals conduct programs statewide to educate communities and individuals and reduce the strain of a growing population on water resources (UF/IFAS, 2011). Extension can be most effective in encouraging the use of good landscape management strategies when they design programs using sound audience research. Minimal research has been conducted on the use of videos to promote behavior change among specific Extension audiences. The information presented here was collected to inform the use of videos as a component of Extension programming for landscape management practices.

\section{Using Videos to Promote Landscape Practices that Protect Water Resources}

Videos are a promising media for Extension because they provide a way for clients to receive new information quickly, reflect on the subject, and may be one of the best ways to encourage behavior change (Friend \& Militello, 2015; Geise \& Baden, 2015; Perrin, 2011). By 2021, videos will likely make up more than $80 \%$ of internet traffic (Cisco, 2017). While Extension needs to use this and other emerging communication and education technologies, research is needed to explore best practices for video use in Extension programming. For example, framing is a communication technique that can be used to communicate complex issues to Extension audiences. Framing refers to presenting the same message in different ways in order to appeal to a particular audience. Framing research has shown that when a message matches an audience's values, the message is more likely to influence the audience's behavior (Scheufele \& Tewksbury, 2007; Shih \& Lin, 2016).

Previous work has shown that print-based messages with personal or social themes are more effective in encouraging landscape water conservation, especially when they convey the benefits of taking action (as opposed to consequences of not acting; Warner, Rumble, Martin, Lamm, \& Cantrell, 2015). Some additional work using printed communications in California revealed the primary messages being used to combat drought negatively influenced participants' attitudes toward water conservation (Liang, Henderson, $\&$ Kee, 2018). These findings hint that it may be better to avoid using videos than to design them inappropriately;

1. This document is AEC639, one of a series of the Agricultural Education and Communication Department, UF/IFAS Extension. Original publication date May 2018. Visit the EDIS website at http://edis.ifas.ufl.edu.

2. Laura A. Sanagorski Warner, assistant professor; Alexa J. Lamm, associate professor; and Joy N. Rumble, assistant professor; Department of Agricultural Education and Communication, UF/IFAS Extension, Gainesville, FL 32611. 
little is known about using and framing videos appropriately to promote good landscape management behaviors.

\section{Evaluating the Effect of Videos on Good Irrigation and Fertilizer Behaviors}

The purpose of the study summarized here was to evaluate the effect of short videos as a tool for encouraging good landscape management behaviors. We surveyed 2,100 Floridians who have a lawn/landscape and use irrigation, because this audience tends to have a greater impact on water resources than those who do not use irrigation (Bremer, Keeley, Jager, Fry, \& Lavis, 2012; Warner, Lamm, \& Rumble, 2017; Warner, Lamm, Rumble, Martin, \& Cantrell, 2016). We tested the effect of four videos on Floridians' intent to use good fertilizer (e.g., prevent spilling of fertilizers on paved surfaces) and good irrigation practices (e.g., prevent irrigation when it is raining). We used intent because individuals who have greater intent to adopt a water protective landscape practice are more likely to engage (Ajzen, 1991).

All of the videos appealed to environmental values by connecting residential landscape practices to the protection of Florida's water bodies. Excluding the gain/loss frames and the fertilizer/irrigation focus, we minimized differences between the videos to ensure we were testing the effect of the frames. The videos were each 30 seconds long and used similar images and scripts so they were consistent except for the frames. The videos were framed differently and incorporated either irrigation or fertilizer practices. Loss or gain frames were conveyed through on-screen text based on the adoption of these best management practices.

Both fertilizer videos presented good fertilizer practices in general, along with a person specifically reading the fertilizer package and cleaning up a fertilizer spill.

- The fertilizer loss video communicated the negative effects of not taking action (using good fertilizer practices) on Florida's water bodies.

- The fertilizer gain video communicated the positive effects of taking action (using good fertilizer practices) on Florida's water bodies.

Both irrigation videos presented good irrigation practices in general, along with a person watering only the landscape and only when needed.
- The irrigation loss video communicated the negative effects of not taking action (using good irrigation practices) on Florida's water bodies.

- The irrigation gain video communicated the positive effects of taking action (using good irrigation practices) on Florida's water bodies.

Videos were embedded in the survey and each of the respondents randomly received only one video or were assigned to a control group (no video). After watching the video, respondents indicated their likelihood of engaging in four good fertilizer (water quality) behaviors: reduce the application of fertilizers to lawn/landscape, engage in good lawn/landscape fertilization practices, apply fertilizers carefully to reduce their runoff into the ground, and prevent spilling fertilizers on paved surfaces; or four good irrigation (water quantity) behaviors: use irrigation only when needed, prevent irrigation when it is raining, conserve water by reducing irrigation, and follow good irrigation practices).

A summary of the results follows.

\section{Fertilizer Videos}

- Of the respondents who watched the fertilizer videos, they were all very likely or likely to intend to use good fertilization practices, apply fertilizers carefully to reduce runoff, and prevent spilling of fertilizer products, despite which video they received. There was no difference in these three behaviors regardless of the videos. Overall, this means videos appealing to environmental values were no more effective for influencing fertilizer behaviors than others. In fact, the findings indicated it is likely that videos appealing to non-environmental values may be more effective on fertilizer practices.

- Those who watched the fertilizer loss video (and were exposed to possible negative consequences of not taking action) were slightly more likely to intend to reduce the application of fertilizers to their lawn/landscape. This means environmental messages targeting residential landscape behaviors may only have an effect when they communicate the consequences of not taking action.

- Among the four water quality behaviors, the greatest number of those who indicated they were undecided was also associated with reducing application of fertilizers compared to the other practices. This finding indicated it may be more difficult to change fertilizer behaviors when Extension clients perceive the change as a reduction in the amount of fertilizer used as opposed to using fertilizers differently. 


\section{Irrigation Videos}

- Of the respondents who watched the irrigation videos, they were all very likely or likely to intend to use irrigation only when needed, prevent irrigation when it is raining, conserve water by reducing irrigation, and follow good irrigation practices, despite which video they received. There was no difference in these four behaviors regardless of the videos. Overall, this means videos appealing to environmental values were no more effective at influencing irrigation behaviors than others. In fact, the findings indicated it is likely that videos appealing to non-environmental values may be more effective on irrigation practices.

- Among the four water quantity behaviors, the greatest number of respondents who indicated that they were undecided received the video associated with conserving water by reducing irrigation. This finding indicated that it may be more difficult to change irrigation behaviors when Extension clients perceive the change as a reduction in the amount of water they use as opposed to using water differently.

\section{How to Use This Information}

Extension professionals who work on landscape and water issues should consider the following when incorporating videos as a tool to encourage good landscape management practices:

- Consider incorporating videos into existing programming efforts. The incredible amount of videos comprising internet traffic highlights an important channel for reaching Extension clientele. However, the videos need to be designed to resonate with the audience, as this study highlights.

- Take the time to test messages whenever possible. We expected these videos to be more effective than they were, highlighting the importance of checking in with the audience and testing an approach before committing substantial resources to an educational campaign.

- Videos appealing to the values a specific audience cares about will likely be more effective. Environmental messages are not always effective. Before using environmental themes, learn about your audience so you can incorporate their values into Extension programs. What do they care about? Perhaps they care more about how their neighbors perceive them or their household finances.

- When Extension clients believe a landscape management practice means using less water or fertilizer, they are unsure about taking action. While the end result might be the same, they are more likely to change a behavior than to reduce their use of a landscape input. Consider presenting best practices as modifications to existing behaviors as opposed to reducing the use of fertilizer or water.

- Extension communications using environmental themes should communicate what can happen if clients do not take action, especially when focused on fertilizer practices. Ensure Extension clients understand how individual landscapes can contribute negatively to local water quality when not managed properly.

- Overall intent to engage in good landscape management practices is high regardless of video treatment, revealing Floridians want to be actively engaged in protecting water resources. Extension can build on this momentum by providing resources and support for clients as they adopt new water protection practices at home. Extension should also provide support after adoption to ensure continued use.

- Remember, it is just as important to share what does not work as what does. The videos we tested were mostly ineffective, and our findings provide important insight into better possible approaches. Extension professionals should share successes and failures as they work to promote protection of Florida's water resources through good landscape management practices.

\section{Conclusions}

Videos are an important educational tool for Extension professionals, but they may not be overly effective when they use environmental themes. Extension professionals should explore creative ways to understand their clientele and appeal to the audience's values while encouraging them to protect water resources.

\section{Acknowledgements}

The authors thank the University of Florida Center for Landscape Conservation and Ecology (http://clce.ifas.ufl. edu) for supporting this publication.

\section{References}

Ajzen, I. (1991). The theory of planned behavior. Organizational Behavior and Human Decision Processes, 50(2), 179-211.

Bremer, D. J., Keeley, S. J., Jager, A., Fry, J. D., \& Lavis, C. (2012). In-ground irrigation systems affect lawn-watering behaviors of residential homeowners. HortTechnology, 22, 651-658. 
Cisco (2017). Cisco visual networking index: Forecast and methodology, 2016-2021. Retrieved from https://www.cisco. $\mathrm{com} / \mathrm{c} / \mathrm{en} / \mathrm{us} /$ solutions/collateral/service-provider/visualnetworking-index-vni/complete-white-paper-c11-481360. html

Friend, J., \& Militello, M. (2015). Lights, camera, action advancing learning, research, and program evaluation through video production in educational leadership preparation. Journal of Research on Leadership Education, 10(2), 81-103.

Geise, S., \& Baden, C. (2015). Putting the image back into the frame: Modeling the linkage between visual communication and frame-processing theory. Communication Theory, 25(1), 46-69.

Hurd, B. H. (2006). Water conservation and residential landscapes: Household preferences, household choices. Journal of the Agricultural and Resource Economics, 31(2), 173-192.

Liang, Y. (J.), Henderson, L. K., \& Kee, K. F. (2018). Running out of water! Developing a message typology and evaluating message effects on attitude toward water conservation. Environmental Communication, 12(4), 541-557. doi: $10.1080 / 17524032.2017 .1288648$

Perrin, J. (2011). Emotional responses to environmental messages and future behavioral intentions. Applied Environmental Education \& Communication, 10(3), 146-157. doi:10 $.1080 / 1533015 X .2011 .603612$

University of Florida Institute of Food and Agricultural Sciences [UF/IFAS]. (2011). Shaping solutions for Florida's future: The University of Florida extension roadmap 2013 2023. University of Florida. Retrieved from http://pdec.ifas. ufl.edu/roadmap/FloridaExtensionRoadmap_2013-2023. pdf

Scheufele, D. A., \& Tewksbury, D. (2007). Framing, agenda setting, and priming: The evolution of three media effects models. Journal of Communication, 57(1), 9-20. doi:10.1111/j.0021-9916.2007.00326.x

Shih, T.-J., \& Lin, C.-Y. (2016). Developing communication strategies for mitigating actions against global warming: Linking framing and a dual processing model. Environmental Communication, 11(6), 840-858. doi:10.1080/17524032. 2016.1154886
Warner, L. A., Lamm, A. J., \& Rumble, J. N. (2017). Can videos play a role in good landscape management practices? Applied Environmental Education \& Communication. Advance online publication. doi:10.1080/153301 5X.2017.1388199

Warner, L. A., Lamm, A. J., Rumble, J. N., Martin, E., \& Cantrell, R. (2016). Classifying residents who use landscape irrigation: Implications for encouraging water conservation behavior. Environmental Management, 58(2), 238-253. doi:10.1007/s00267-016-0706-2

Warner, L. A., Rumble, J. N., Martin, E., Lamm, A. J., \& Cantrell, R. A. (2015). The effect of strategic message selection on residents' intent to conserve water in the landscape. Journal of Agricultural Education, 56(4), 59-74. doi:10.5032/jae.2015.04059 